\title{
A Framework for Serious Games in High Education \\ ${ }^{1}$ Pedro Ramos Brandao (PhD), ${ }^{2}$ Sandra Gama (PhD) \\ ${ }^{1,2}$ Instituto Superior de Tecnologias Avançadas (ISTEC)
}

\begin{abstract}
:
With the ubiquity of technology, we have nowadays, many processes have taken advantage of information technology mechanisms to leverage their outcomes. Education is not an exception. In fact, technology has been playing an increasingly important part in learning experiences. For instance, game elements have been effectively used in educational settings, with very promising results. Hence, we propose a framework for applying game elements in a serious game to be used in higher education settings. It comprises a set of game mechanisms and leverages the importance of a coherent narrative and collaboration. We have deployed this framework in an instance of an engineering course as proof of concept, with promising results. Extensive empirical testing will be conducted, with advanced statistical analysis, to validate our framework. It will then be a tool to be used by educators to enhance learning processes.
\end{abstract}

Keywords: Serious Games, Education, Gamification, Gameful Learning, Gaming in Education..

\section{Introduction}

The paradigm shift that technology has brought implies the need for education processes to be updated. In fact, more and more learning processes throughout the curricula of different universities take advantage of information technologies. Nevertheless, even in innovative approaches, traditional methods are often ineffective, failing at creating motivation and engagement in students.

Game elements have been successfully used in a variety of educational settings. Hence, the aim of our work and its main contribution is the creation of a framework to create effective serious games in higher educational settings.

One of the most important principles we must consider is Engagement. Students who are deeply involved in the learning process are more likely to have a satisfying experience and higher grades. In a game, the narrative plays a major role in creating engagement. We propose the adaptation of a wellknown and commonly used template for storytelling to our context to further involve students in the game.

Another important feature that must be considered to attain engagement is personality. In fact, it defines the way in which people react to stimuli. If taken advantage of, personality can help adapt the game experience to different needs, further enhancing engagement.

Lastly, we emphasize the importance of collaboration and the combination of social, teaching, and cognitive presence.

\section{Satate of Art}

The integration of information technologies in teaching and learning processes has increased significantly in recent years [1]. The terminology of information technology tools in education doesn't mean exclusively the provision of computers and software, it implies a different posture on the part of teachers, that is, it implies a paradigm shift. This change encompasses the mechanisms such as hardware and software, as well as new methodologies, namely with the predominance of multimedia in curriculum development [1].

C. Abt [2], defined and explained that the use of Serious Games (S.G.) could and should be one of the educational mechanisms to be employed in this new paradigm, nevertheless, excluding the possibility of this educational tool being framed only as a form of entertainment, (S.G.) are something that is beyond 
entertainment, strict census, which doesn't mean that (S.G.) don't have this playful component, they do, and it furthers the educational purpose [2].

J. Huizinga [3], on the other hand, complements this concept by noting that (S.G.) have a component of freedom and awareness of responsibility for the student, where his creativity can be stimulated and become an immersive process through the student's absorption in the game itself, forgetting that it is eminently a teaching process [3].

D. Michael [4], advocates that In a broad sense, educational games for learning make up a subset, though educational, or at least training, and there are aspects that are always involved in the design of a serious game, if regarded under the standards of the traditional definition. Nevertheless, according to R. Schmidt [5], this array of definitions of (S.G.) and related genres, such as game-based learning, further complicates the debate around these very terms. There are cases where scientific games applied to citizens in general, according to M. Baaden and A. Dippel [6,7], in which players collaboratively generate data on scientific activities, they are also seen as (S.G.). In an effort to move over this "generation," others have tried to establish more holistic concepts and expressions, namely, "explicit games", this in the opinion of R. Schmidt [5].

Nonetheless, despite these discussions and lasting efforts, the term (S.G.) is still widely used in the academy and industry.

According to M. Carvalho [8], (S.G.) must not simply be defined as digital games designed with added educational and entertainment value, as mere "decorative" artefacts: educational features must be present in the whole game design. (S.G.) have been growing in importance within the educational field, and offer good learning class, according to S. Freitas [9]. In P. Backlund's [10] opinion, they have been proven successful in many cases for learning, competence development, and more than that, they bring learning retention, and there are results that suggest they enhance the acquisition of knowledge.

According P. Wouters and T. Connolly [11, 12], More than this, they add an important feature to the teaching process, namely, motivation.

Nevertheless, according to S. Vandercruysse [13], positive results depend on many variables ranging from students' backgrounds to aspects of game design as well as the contents to be taught. According to the same author, in this sense, works on (S.G.) are always a necessary and important contribution as an addition of knowledge to previous works, among other important aspects, which indicates a continuous growth of (S.G.) investigation. This feeds into the current status of the research in relation to S. G. which do support learning. According to S. Marsh [14], despite its broader definitions, as noted above, (S.G.) are made so that the gamer intends to learn something, to practice some skill, or to acquaint himself with skills, on the other hand, according to V. Nieto and E. Baalsrud [15, 16], unquestionably because they frequently have considerable potential in the learning and teaching process, they are frequently mistaken for the subgroup of educational games. The successful use of (S.G.) offers room for challenges in the teaching - learning process, namely if these games are adaptable; if they set clear objectives and targets; if they allow or even induce collaboration between players and the students; whether this collaboration is accomplished through engagement; as well as if people are satisfied when they are playing them - true immersion is appropriate [16].

(S.G.) are also associated with play-based learning (PBL). There is a number of authors, according to whom, such as M. Molina and M. Qian [17, 18], game-based learning, stands for any learning process which is driven, prompted, or inspired, induced, or motivated by a game (either digital or physical) - or by a series of them. Or physical) game - or a numerous author, such as C. Deguirmendjian [1] and A. Miljanovic [19], for instance, currently conduct studies that were related to (S.G.) and game-based learning (GBL).

According to G. Cerinsek [20], the key aspect in game-based learning (PBL) is to make use of games as stimulus to engage and enhance students in their learning processes, and to function as helping mechanisms in teaching processes. In game-based learning (GBL), with the use of games, the teacher's primary role becomes motivating and empowering the students' knowledge for the development of a deep and meaningful learning. 
However, according to M. Shah [21], to adequately reach this goal with digital games, educators are required to have a solid understanding on how to combine Information and Communication Technologies into curricula and programs, as well as how to integrate game-based learning activities into the classroom.

On the other hand, according to R. Bock [22], the player's experience in a serious game will be problemdriven, whilst entertainment games will usually be action-packed and with many possibilities. Moreover, according to this author, it is recommended to create the story in a serious game that is based on player action, whereas in an entertainment game aleatory features are usually added.

\section{Principles for a Serious Game in Education}

We propose a framework comprising a set of game elements to be used in a serious game that is capable of engaging and motivating students in higher education, while generally improving learning processes.

The main aspects that contribute to the success of a serious game, as previously mentioned, have to do with (i) being adaptable, (ii) propose clear objectives, (iii) allow or even induce collaboration, and (iv) generate player satisfaction [16].

Over the next sections we clarify the main principles in which our framework is based, aiming at meeting the aforementioned features. We follow a used-centered approach and take the specificities of serious games into account.

A. Engagement and Motivation

A successful game is one which generates player satisfaction through motivation and engagement. In learning settings, such a game will serve not only as a trigger to involve students in pedagogical activities but also as an auxiliary tool in learning [17,18]. We discuss the importance of storytelling and adaptation mechanisms for narrative coherence and motivation, respectively, as well as the potential of collaboration to enhance student engagement.

In the light of this, we derive a set of features to be used in a serious game that instantiates such measures through gameplay mechanics.

According to Chorianopoulos et al., one of the principles in educational serious game design is to engage students with the narrative [23]. In fact, effective storytelling has the potential to generate suspension of disbelief and consequentially contribute to narrative coherence. Hence, if we guide the experience by a problem, but with a story [22], our serious game will gain another dimension and, therefore, be more engaging.

One of the most commonly used templates for storytelling is the Hero's Journey or monomyth [24]. Not only is it used in several movies and video games, but it has also, in fact, been adopted in educational settings [25]. The Hero's Journey is a narrative template involving a hero who goes on an adventure, wins a challenge and is shaped by that experience. There are several variations of this journey, comprising eight, twelve or 17 stages, depending on which interpretation the author chooses. In a serious game, usually the player will be the main character.

It may be summarized as follows:

1)At the beginning, the protagonist is introduced, with some sort of potential disruptions;

2)The potential disruptance reveals itself and the protagonist is challenged. (S)he decides whether to accept the challenge;

3) When (s)he accepts the challenge, the protagonist finds a resource that will enable them to face the challenge. (S)he commits to overcoming it and starts the adventure;

4) The main character faces his/her enemies with the help of his/her allies, in a series of smaller challenges;

5) They are then confronted with a more significant challenge. Overcoming it will prepare the hero for the rest of the journey. 6) (S)he then overcomes the final test and completes his/her initial quest. (S)he retains the experience as a life-changing situation which shaped his/her life.

In this light, we propose the establishment of a storyline which aligns with the hero's journey. It may be summarized as follows: 
(i) There is a major quest to be overcome which triggers the beginning of the game;

(ii) The quest includes smaller challenges. While some are individual missions, others may involve collaboration or competition;

(iii) After completing the smaller challenges, a more significant challenge arises which will grant extra preparation for the remaining journey;

(iv) There is a resource or a pool of resources that may be unlocked which will aid in overcoming the challenges;

(v) The player faces one last challenge on his/her own: the hero's final test;

(vi) After completing the quest, the player receives a reward.

Creating a narrative which involves the player as the main character (hero) will not only create a more engaging experience but also keep him/her motivated throughout the game, generating satisfaction.

Despite the widespread success of serious games in a myriad of settings, one common shortcoming is that, not quite uncommonly, they fail to engage some people. To alleviate this problem, one must consider that personality plays a major role in the way that people react to stimuli. This can be used to adapt the game experience to any type of player, enhancing the game experience and, consequently, improving success.

A well-known and frequently used classification of player types regarding personality is Bartle's Taxonomy [26], in which he identified four types of players: (i) Achievers, whose engagement comes from extrinsic motivation (accumulating points, rising in levels, seeing their progress, collecting badges); (ii) Explorers, who enjoy exploration and unpredictability; (iii) Socializers, the ones seeking collaboration and inter-playing relationships; (iv) Killers, who want to see others outplayed, preferably with a high damage, while they prevail. While the first two types of players are concerned about the world (either to act in it or explore it), the last two are concerned about other players (either to interact or to kill).

Despite this being a widespread taxonomy, more recent classifications have been proposed. Nacke et al. [27] introduced the BrainHex model which is based on neurobiological findings. This model presents seven player archetypes: (i) Seekers are motivated by the game world and its mechanisms; (ii) Survivors pursue an adrenaline rush, obtained through fear and intensity; (iii) Daredevils enjoy taking risks and like playing on the edge while still in control; (iv) Masterminds enjoy strategic thinking and puzzle solving; (v) Conquerors seek to overcome difficult challenges; (vi) Socializers are people-oriented, so they look for interactions and collaboration; (vii) Achievers get satisfaction from attaining their goals.

The memory association are of the brain is the one that is more highly activated for Seekers, while Survivors' and Daredevils' excitement is stimulated by epinephrine, a neurotransmitter related to the amygdala. Masterminds depend on the decision center of the brain and Conquerors' motivation by anger is determined by the hypothalamus. Lastly, Socializers' and Achievers' behaviour is related to two neurotransmitters, oxytocin and dopamine, respectively.

Nevertheless, the User Type Hexad, slightly more recently, has taken predominance over several serious games and gamification experiences [28]. Instead of relying user behaviour itself, as considered in Bartle's approach, this model presents six types of player, either related to one of four intrinsic motivation mechanisms or other motivations. The Hexad model's player types may be summarized as follows: (i) Socializers, who seek Relatedness and interaction with other players; (ii) Free Spirits, autonomous players looking for exploration; (iii) Achievers who, motivated by Mastery, pursue new challenges and skills; (iv) Philanthropists, who rely on Purpose and Meaning to aim at improving other people's experiences; (v) Disruptors are motivated by Change and try to disrupt the system to achieve it; (vi) Players, look for Rewards and their behaviour reflects their need to collect them.

Considering the aforementioned taxonomies, one can ascertain player types and adopt different game mechanisms to adapt the game experience to fit different types of players. Instead of relying on a onesize-fits-all approach, an adaptable game experience based on player profiles may in fact enhance engagement in a serious game, thus improving player satisfaction. 


\section{B. Collaboration}

Collaboration in education is not a new concept. It has in fact been used for decades in a wide variety of pedagogical settings. Nevertheless, and despite the relationship between collaborative learning and constructive cognitive development pointed out by Piaget [29], students in higher education are generally expected to learn individually [30].

With the technological advance we have been presented with over the last decades and the profusion of online or blended educational settings, many instructors have taken advantage of collaboration to enhance learning processes. There are, however, several factors that contribute to the success of this approach [31]. For instance, timely feedback, the promotion of knowledge-building communities and the establishment of balanced team-dynamics seem to be of paramount importance. Macdonald [32] stresses the complexity of the process and the importance of adopting collaborative activities that are tied to the course assessment. We should also consider that social, teaching and cognitive presence must be combined to reach an effective collaborative learning environment [33]. In our game concept, which we will describe in the following section, we propose a set of activities that take these aspects into account to deploy a successful collaborative learning setting. Nevertheless, the way in which these activities are adopted must be carefully considered. In fact, it must be articulated with a coherent narrative and integrated in a way that adjusts to different player types.A suitable instantiation of collaboration principles, coupled with adaptable game mechanisms and an adequate storyline will provide educators with the means for the deployment of a successful serious game in higher education, potentially leveraging learning processes.

\section{Prof of Concept}

We have deployed our game concept in the spring semester of a higher education course at [omitted for blind review] with a 16-week duration, attended by eight students $(\mathrm{N}=8)$. At the beginning of the course, we applied a game profile questionnaire (in this case, BrainHex [27]). Our students were either Conquerors $(\mathrm{N}=5)$, Seekers $(\mathrm{N}=2)$ or Achievers $(\mathrm{N}=1)$. In terms of subclasses, we had two Seeker-masterminds $(\mathrm{N}=2)$, one Conqueror-achiever $(\mathrm{N}=1)$, one Conqueror-daredevil $(\mathrm{N}=1)$, one Achiever-conqueror $(\mathrm{N}=1)$, one Conqueror-seeker $(\mathrm{N}=1)$, one Conqueror-survivor $(\mathrm{N}=1)$ and one Seeker-conqueror $(\mathrm{N}=1)$. We included an additional question, which students had to answer using a five-point Likert Scale [1: totally disagree - 5: totally agree] "I like to compete for grades". Results are presented in Figure 1.

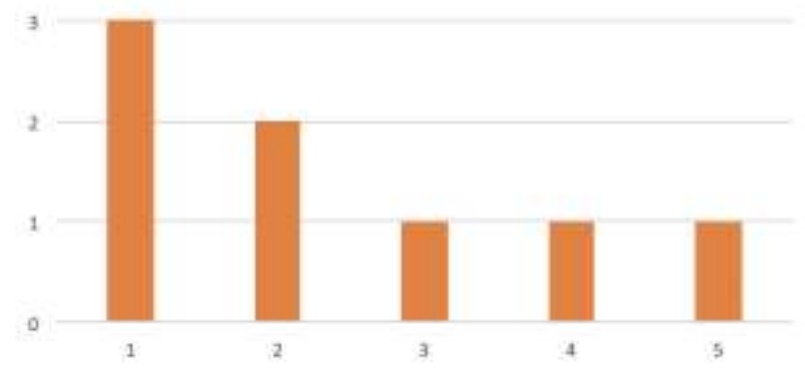

Figure 1. Answers to the question "I like to compete for grades".

The results for this question were interesting if we look at the BrainHex results. Despite more than half of the students being conquerors, most state that they do not enjoy competing for grades. Hence, we emphasized collaboration through group work and forum discussions.

In this instance of the course, grade points were converted into XP, with a maximum of 40.000 XP. Students could get points from the following activities:

1)Two quizzes, the course Scrolls (10.000 XP each);

2)Two Hands-on exercises (5.000 XP each), done in groups;

3)A project, the course Quest (8.000 XP), done in groups;

4)Answering initial and final questionnaires (2.000 XP). 
To pass the course, students must do an exam, which we named Course Boss, with a grade higher or equal to $10.000 \mathrm{XP}$.

The goals match the Hero's Journey, considering its main stages features (smaller, enabling trials, a major quest afterwards and a final challenge. We reserved some "bonus" points for questionnaires to motivate students to participate. At the beginning of the course, we applied the BrainHex questionnaire, as described before, and at the end we applied a final questionnaire to enable the assessment of course engagement and motivation. We will further describe this questionnaire, along with the results, in the next section.

In terms of game mechanisms, a Leaderboard was used, which featured the rank of each player, their picture and name, the total amount of XP, as well as the current level and its description. The level was computed by adjusting the XP scale to a 20-point grade and the description consists of a simple, game-like affirmation. The final Leaderboard may be seen in Figure 2, where player names and pictures were anonymized for personal data protection.

\begin{tabular}{|c|c|c|c|}
\hline \multicolumn{5}{|c|}{ Leaderboard } \\
\hline Rank & Player & XP & \multicolumn{1}{|c|}{ Level } \\
\hline 1 & C37375 & 19 Unlocking the next levell \\
\hline 2 & & 36250 & 19 Unlocking the next levell \\
\hline 3 & & 34250 & 18 Slaying bosses \\
\hline 4 & & 33875 & 17 Slaying enemies \\
\hline 5 & & 30500 & 16 Expanding inner strenght \\
\hline 6 & & 30000 & 15 Acquiring secret scrolls \\
\hline 7 & & 25375 & 13 Measuring strengths \\
\hline 8 & & 1000 & 1 Let the games begin! \\
\hline
\end{tabular}

Figure 2. Final course Leaderboard

The Leaderboard was updated with each activity and published immediately afterwards (in the same day as each activity). Additionally, we promoted forum discussion for the discussion of ideas, clarification of course concepts and any other questions that might arise.

\section{A. Evaluation}

At the end of the course, we applied a questionnaire comprising a set of eight questions, most using a fivepoint Likert scale [1: totally disagree -5 : totally agree]. The questions were as follows:

1)How involved were you in this course?

2)How involved were you in this course, compared to other courses?

3)How much did you participate in class, compared to other courses?

4)How much do you agree with the following affirmation: "This course's assignments require a more creative approach compared to other courses"?

5)How important is it for you to get a high grade?

6)How important is it for you to be challenged?

7)If you had to choose between getting a high grade and being challenged, which one would you choose?

8)How fun were the game elements (XP, Leaderboard, Game Levels, Practical Assignments)?

The intent of this questionnaire was twofold: while questions 1, 2, 3, 4 and 8 aimed at assessing course engagement, the goal of questions 5, 6 and 7 was to understand the preponderant type of motivation for this groups of students.

Results for questions 1 through 6, and 8 [the ones using a Likert-scale] are presented in Figure 3. As for question 7 , all participants stated that they prefer to be challenged $(\mathrm{N}=8)$. 


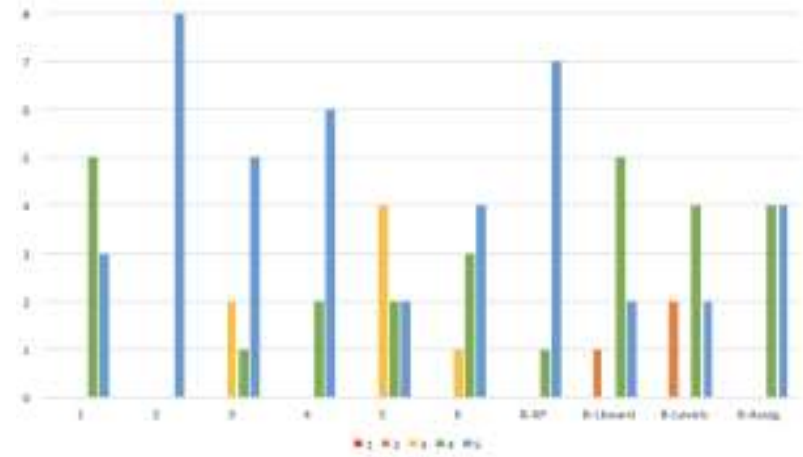

Figure 3. Results for questions 1 through 6 , and 8 , of the final questionnaire.

B. Discussion

Looking at the questions, the first aspect that we assess is involvement. In fact, not only were students highly involved in this course (Question 1) (Score:4, N=5; Score:5, N=3), but all agree that they were more involved in this course when compared to other courses (Question 1) (Score:5, N=8). In terms of participation (Question 3), we can see that our results are very promising as well: most students participated more in this course compared to others (Score:4, N=1; Score:5, N=5), two were neutral (Score:3, N=2), and never the opposite. Looking into the results for Question 4, participants found this course to require a higher creativity than others, which is very interesting, considering that this course is part of a Multimedia Engineering Study Programme and requires a considerable amount of programming, unlike many others in which students must create multimedia content. Continuing to analyse the results for engagement, Question 8 results show that XP generated more fun (Score:4, N=1; Score:5, N=7), followed by the Hand-on challenges and the Quest (practical group assignments) (Score:4, N=4; Score:5, N=4), the Leaderboard (Score:2, N=1; Score:4, N=5; Score:5, N=2) and Levels (Score:2, N=2; Score:4, N=4; Score:5, N=2).

In terms of motivation, we must look at the results for questions 5, 6 and 7. Effectively, students feel that it is more important to be challenged (Question 6) (Score:3, N=1; Score:4, N=3; Score:5, N=4) than to have a high grade (Question 5) (Score:3, N=4; Score:4, N=2; Score:5, N=2). When faced with the decision, all $(\mathrm{N}=8)$ chose the challenge over the high grade. These results are very interesting and are in line with the additional question we applied in the initial questionnaire "I like to compete for grades", in which most students stated that they do not like this type of competition.

In this light of these results, we can conclude that students like to feel challenged and that they are, though the need for creative solutions that they had to look for when completing the tasks of the game. Furthermore, their involvement and consequent engagement in the game shows that they completed the course with a high satisfaction.

\section{Conclusion}

With the technological advances we have been faced with over the last decades, educational settings have evolved to a point where information technologies are often an important part in learning processes. The use of game elements has proven effective in a variety of educational settings. We propose a framework which takes advantage of game elements for a serious game to be used in a higher education context. Having deployed these features in an instance of a course, along with clearly defined objectives using a coherent and holistic narrative, and collaboration mechanisms, we could verify enhanced student engagement. However, we have presented a proof of concept, in which we have conducted an experiment with a limited number of participants and. Extensive empirical testing with advanced statistical analysis must be conducted to validate our framework and its mechanisms throughout the different instances of the course.

The fact that the course provides some flexibility helps students choose part of their path throughout the game. Nevertheless, leveraging on further adaptation will enable the game to more promptly address individual differences and potentially show even more promising results. These adaptation mechanisms must stem from the results obtained from classification of player types regarding personality so that we can meet our players' needs. Such adaptation must encompass additional game elements that must be integrated and widely tested throughout the different instances of the game.

We intend to adopt the GEQ as a tool to further measure engagement. Looking at the results of this questionnaire will help us understand which aspects we can improve in terms of engagement and, if applied 
in different instances of the course, which mechanisms we must emphasize for further success.

\section{References}

1. C. Deguirmendjian, "Serious game developed in health", J. H. I., 8, (2016).

2. C. Abt, "Serious game developed in health: integrative literature review", J. Health Inform, 2016.

3. J. Huizinga, "Essay on the social function of the game", Gallimard, 1951.

4. R. Michael, "(S.G.): game that educate, train, and inform”, Muska \& Lipman, 2005.

5. R. Schidt, "Applied games search of a new definition”, International Conference on Entertainment Computing, 2015.

6. M. Baaden, "Ten simple rules to create a S. G.", AE, 2018.

7. Dippel, "Laborious Playgrounds: citizen science games as new modes of work play in digital age", Amsterdam U. P., 2018.

8. Carvalho, "An activity theory-based model for (S.G.) analysis and conceptual design", C. E., (2015).

9. S. Freitas, "Are games effective learning tools? A review of educational games", J. Educ. Technol. Society, 2018.

10. P. Backlund, "Educational games-are they worth the effort?" In: $5^{\text {th }}$ international conference on games and virtual worlds for S.G., 2013.

11. P. Wouters, "A meta-analysis of the cognitive and motivational effects of (S.G.)", J. E. P., 2013.

12. M. Connolly, "A systematic literature review of empirical evidence on computer games and (S.G.)", Comput. Educ., 2012.

13. S. Vandercruysse, "Game base learning." In: handbook of research on (S.G.) as E. B. R. tools, 2012.

14. T. Marsh, "Slow (S.G.), interactions an play: designs", E. C., 2016.

15. V. Guillén-Nieto, "(S.G.) and learning effectiveness", Comput. E., 2012.

16. J. Baalsrud, "Perspectives on accessibility in digital games", ICEC 2018, 2018.

17. E. Ruiz-Molina, "Information and communication technology", J. F. B. R., 2014.

18. M. Qian, "Game-based Learning an $21^{\text {st }}$ century", C. H. Behav. 2016.

19. Mijanovic, "A review of (S.G.) for programming", JCSH, 2018.

20. G. Cerinsek, "Recommendations to leverage game-based learning", JCSG 2017, Springer, 2017.

21. M. Shah, "Developing and assessing teachers of game-based learning", J.T.T.E., 2015.

22. R. Bock, "(S.G.)”, Games for Learning, 2018.

23. K. Chorianopoulos, M. Giannakos, and N. Chrisochoides. Design Principles for Serious Games in Mathematics. In Proceedings of the 18th Panhellenic Conference on Informatics (PCI '14). ACM, New York, NY, USA, 1-5. 2014

24. J. Campbell, The hero's journey: Joseph Campbell on his life and work (Vol. 7). New World Library, 2003.

25. J. Brown and C. Moffett. The hero's journey: How educators can transform schools and improve learning. ASCD. 1999.

26. R. Bartle, Hearts, clubs, diamonds, spades: Players who suit muds. 1996.

27. L. Nacke, C. Bateman, R. Mandryk, Brainhex: A neurobiological gamer typology survey. Entertainment Computing 5. 2013.

28. Marczewski. User Types HEXAD. 2015.

29. J. Piaget, The child's conception of the world. London: Kegan Paul, Trench \& Trubner, 1929.

30. L. Gaillet, A historical perspective on collaborative learning. Journal of Advanced Composition, 93 $110,1994$.

31. T. Roberts, Online Collaborative Learning: Theory and Practice. IGI Publishing. 2003

32. J. Macdonald, Assessing online collaborative learning: process and product, Computers \& Education, Volume 40, Issue 4, p. 377-391, 2003.

33. P. Redmond, J. Lock, A flexible framework for online collaborative learning, The Internet and Higher Education, Volume 9, Issue 4, p.267-276, 2006.

34. W. IJsselsteijn, Y. de Kort and K. Poels, The Game Experience Questionnaire. Technische Universiteit Eindhoven, 2013. 